\title{
Perancangan Purwarupa Pengatur Suhu Otomatis pada Inkubator Penetasan Telur Ayam Menggunakan Arduino Uno dan Sensor Suhu IC LM 35
}

\author{
Deny Nusyirwan ${ }^{1}$, Muhammad Farudin ${ }^{2}$, Prasetya Perwira Putra Perdana ${ }^{3}$ \\ ${ }^{1,2,3}$ Fakultas Teknik, Program Studi Teknik Elektro, Universitas Maritim Raja Ali Haji (UMRAH) \\ ${ }_{1,2,3} \mathrm{Jl}$. Politeknik Senggarang, Tanjungpinang 29100 \\ Email: 'denynusyirwan@umrah.ac.id, ${ }^{2}$ muhammadfahrudin1210@gmail.com, ${ }^{3}$ pras.perwira@gmail.com
}

\begin{abstract}
ABSTRAK
Perkembangan teknologi elektronika telah menciptakan suatu kemudahan dalam melakukan pekerjaan terutama yang membutuhkan waktu yang lama sebagai contoh adalah teknologi penetas telur ayam. Jika dilaksanakan secara manual maka peternak ayam harus melakukan pemindahan telur secara manual, memantau keadaan suhu yang ditetapkan per jam atau mengatur suhu yang diharapkan dengan melakukan percobaan berkali-kali. Dengan menggunakan alat pengatur suhu otomatis maka peternak hanya memerlukan waktu sekali saja yaitu meletakkan telur dan meletakkan sensor dalam inkubator telur. Penelitian ini akan membahas tentang perangkat keras dan perangkat lunak yang meliputi Bagaimana merancang alat kontrol pada inkubator penetas telur yang terbuat secara manual kontrolnya menjadi kontrol otomatis yang terdiri dari Arduino uno, lampu sebagai sumber panas, sensor panas, layar LCD sebagai pembaca sensor suhu aktual dan kipas sebagai penstabil suhu ruangan. Dari hasil pengujian alat dapat berfungsi dengan baik yaitu suhu dibuat set point $38^{\circ} \mathrm{C}$, jika melebihi panasnya $>38^{\circ} \mathrm{C}$ maka kipas akan hidup untuk menstabilkan suhu menjadi $38^{\circ} \mathrm{C}$.
\end{abstract}

Kata Kunci : perancangan; sensor suhu; arduino; penetas telur ayam

\begin{abstract}
The development of electronic technology has created an ease in doing work especially those that require a long time as an example is the chicken egg incubator technology. If carried out manually, the chicken farmer must manually transfer the eggs, monitor the temperature set by the hour or set the expected temperature by experimenting many times. By using an automatic temperature controller, the farmer only needs one time to put the egg and put the sensor in the egg incubator. This study will discuss hardware and software which includes how to design a control device on a manually-controlled egg incubator for automatic control which consists of Arduino uno, a lamp as a heat source, a heat sensor, an LCD screen as an actual temperature sensor reader and fan as a room temperature stabilizer. From the results of testing the tool can function properly, ie the temperature is set to $38^{\circ} \mathrm{C}$, if it exceeds the heat $>38^{\circ} \mathrm{C}$, the fan will turn on to stabilize the temperature to $38^{\circ} \mathrm{C}$.
\end{abstract}

Keywords : design; temperatur sensor; arduino; chicken egg hatcher

Cara Mengutip : Nusyirwan, D., Fahrudin, M. Perdana, P., (2019). Perancangan Purwarupa Pengatur Suhu Otomatis pada Inkubator Penetasan Telur Ayam Menggunakan Arduino Uno dan Sensor Suhu IC LM35. JAST: Jurnal Aplikasi Sains dan Teknologi, 3 (1), 60-72. http://dx.doi.org/10.33366/jast.v3i1.1315 


\section{PENDAHULUAN}

Pada peternak ayam umumnya mempergunakan sebuah inkubator untuk menetaskan telur ayam. Dalam inkubator tersebut terdapat lampu yang di pakai untuk menghangatkan telur sehingga telur dapat menetas dengan kualitas baik dengan mempergunakan lampu pijar. Namun pada umumnya dalam proses penetasan telur tersebut sering terjadi beberapa hambatan, diantaranya adalah inkubator hanya mempergunakan lampu pijar saja tanpa ada alat notifikasi bahwa telur ayam telah menetas maupun pemberitahuan bahwa lampu pijar mati, tidak adanya deteksi suhu pada inkubator tersebut dan kurangnya perhatian secara serius dalam pengembangan ternak telur ayam. Sering terjadinya lupa memisahkan hasil ayam yang telah menetas yang mengakibatkan penumpukan ayam di inkubator. Biasanya peternak menggunakan inkubator dengan harga yang relatif mahal dengan spesifikasi inkubator hanya lampu pijar dan alas inkubator saja yang mengakibatkan peternak mengurangi biaya modal ternak telur ayam serta tidak mendapatkan informasi yang terdapat di inkubator tersebut. Dengan berkembangnya teknologi saat ini yang semakin canggih dan sejalan dengan revolusi industry 4.0, penggunaan teknologi semakin meningkat, maka dirancang sebuah purwarupa pengatur suhu otomatis pada incubator penetasan telur ayam pada Arduino Uno dan sensor suhu IC LM35.

Salah satunya perangkat kontrol adalah mikrokontroler Arduino merupakan kit elektronik atau papan rangkaian elektronik yang di dalamnya terdapat komponen utama yaitu sebuah chip mikrokontroler dari perusahaan Atmel serta software pemrograman yang berlisensi open source Saat ini Arduino sangat popular di seluruh dunia. Banyak pemula yang belajar mengenal robotika dan elektronika lewat Arduino karena mudah dipelajari. Tapi tidak hanya pemula, para professional pun ikut senang mengembangkan elektronik menggunakan Arduino. Bahasa yang dipakai dalam Arduino bukan assembler yang relatif sulit, tetapi Bahasa $\mathrm{C}$ yang disederhanakan dengan bantuan pustakapustaka Arduino. Disamping itu, salah satu tools untuk mengatur program Arduino adalah aplikasi Arduino versi 1.6.10. Aplikasi ini yang digunakan untuk membuat program yang dikhususkan untuk Arduino Uno. Mikrokontroler adalah sebuah chip yang berfungsi sebagai pengontrol rangkaian elektronik dan umumnya dapat menyimpan program di dalamnya. Inkubator adalah alat yang dipanasi dengan aliran listrik pada suhu tertentu yang dipakai untuk mengerami telur, mikroba dan menghangatkan bayi yang lahir prematur. Saat menggunakan inkubator untuk pengeraman mikroba sebaiknya tidak terlalu penuh atau kelebihan kapasitas karena hal itu dapat memperbesar risiko kontaminan. Hal pertama yang perlu dilakukan sebelum menggunakan inkubator adalah mengatur alat dan bahan dan memasukkannya ke dalam inkubator dengan susunan efektif.

\section{Penelitian terdahulu}

Pada penelitian yang berjudul Simulasi sistem pengontrol suhu pada mesin pentas telur berbasis mikrokontroller AT59C52 adalah sebuah 
penelitian untuk menjaga suhu didalam mesin penetas telur tetap stabil sesuai dengan temperatur yang dibutuhkan pada proses penetasan. Mengunakan bahasa pemograman $\mathrm{C}$ dan mempergunakan sensor suhu yang akan mendeteksi suhu didalam inkubator. Apabila suhu mencapai suhu dibawah $38,3^{\circ} \mathrm{C}$, maka mikrokontroller akan menerikan perintah kepada mesin pengerak, dan begitu juga sebaliknya apabila suhu berada diatas suhu maksimal $40.5^{\circ} \mathrm{C}[1]$.

Sedangkan pada penelitian dengan judul Rancang bangun otomatisasi mesin penetas telur sistem turning berbasis mikrokontroler ATMEGA 328 menjelaskan sebuah aplikasi sistem pengendalian suhu dengan sistem putar (turning) pada mesin penetas telur sehingga telur dapat menetas secara bersamaan. Sistem putar ini bertujuan untuk menghindari embrio yang menempel pada kulit telur. Mikrokontroller akan mendeteksi suhu untuk mengatur kerja dari lampu pijar sebagai penghasil panas dan kipas untuk mengeluarkan panas apabila sudah diatas suhu maksimal. [2]

Penelitian dengan judul Perbandingan kinerja mesin penetas telur otomatis dengan menggunakan kontrol On-Off dan kontrol PWM menjelaskan mengenai pentingnya menjaga suhu pada mesin penetas telur seara akurat dengan menggunakan kontrol PWM dengan interval suhu 0.3 detik dan arduino nano. Dari hasil perbandingan dengan menggunakan kontrol On-Off, maka didapatkan bahwa pengontrolan dengan PWM dapat meningkatkan hasil penetasan [3].
Adapun penelitian dengan judul Aplikasi sistem kendali temperatur otomatis pada mesin penetas telus ayam menggunakan sistem fuzzy logic, sistem ini menggunakan mikrokontroler ATMeg16 yang akan mengatur lampu pijar dan kipas, selain itu juga menggunakan saklar on-off untuk menghindari apabila terjadi gangguan. Adapun sensor suhu yang dipergunakan adalah SHT11 [4].

Pada penelitian dengan dengan judul Perancangan mesin otomatis penetas telur berbasis NodeMCU dan android menggunakan sistem pamantauan suhu dan kelembaban nirkabel. Dengan menggunakan sensor suhu DHT11 maka suhu pada ikubator akan didapatkan, selanjutnya mikrokontroller akan mengirimkan data melalui wifi ke android. Selain itu juga menggunakan lampu pijar dan kipas untuk membantu pengontrolan suhu didalam inkubator [5]

\section{METODE KEGIATAN}

Peranan penting bagi ilmuwan pada abad ke-21 adalah berperan serta dalam mendidik masyarakat tentang metode dan hasil proses ilmiah [6], oleh sebab itu diperlukan proses desain rekayasa untuk mampu menghasilkan inovasi berbasiskan teknologi yang semakin berkembang dan memiliki fungsi yang tepat dan mudah untuk digunakan. Jika di masa lalu desainer dievaluasi hanya berdasarkan pada keterampilan teknis mereka, di masa depan akan lebih banyak lagi kebutuhan untuk desainer yang bersedia bekerja dengan pendekatan yang lebih sistemik dan strategis dalam skala yang lebih besar [7]. Adapun penelitian ini menggunakan 
konsep Proses Desain rekayasa. Lihat

\section{Gambar 1.}

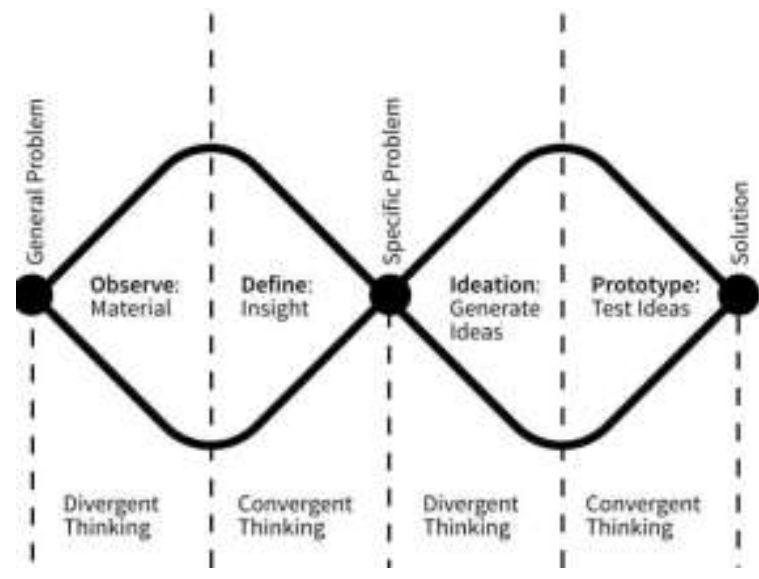

Gambar 1. Tahapan pada Proses Desain Rekayasa [8]

Proses Desain Rekayasa adalah merupakan sebuah proses didalam mendesain dengan berpusat kepada pengguna. Dimulai dengan etnografi hingga menghasilkan sebuah purwarupa yang merupakan sebuah konsep solusi yang sesuai dengan kebutuhan di masyarakat.

Proses ini memiliki 4 tahapan, pada tahapan awal dimulai dengan observasi secara luas di masyarakat untuk mendapat permasalahan, tahapan kedua adalah proses pengerucutan dengan melakukan pemilihan permasalahan utama, tahapan ketiga adalah mengembangkan ide-ide sebagai solusi terhadap permasalahan utama dan tahapan terahir adalah menetukan solusi utama untuk dapat dilanjutkan ke tahapan pembuatan purwarupa dan pengujian terhadap pengguna. Dalam tahapan pengujian terhadap pengguna akan terdapat proses iterasi untuk mendapatkan masukan untuk perbaikan inovasi nantinya.
Desain dan pemasaran adalah dua bagian penting dalam proses penelitian untuk melakukan pengembangan produk dan menghasilkan inovasi berbasis teknologi. Kedua bidang tersebut dapat saling melengkapi namun memiliki fokus yang berbeda. Peneliti untuk bidang desain sangat ingin tahu apa yang benarbenar dibutuhkan oleh calon pengguna dan bagaimana sebenarnya pengguna akan menggunakan produk yang sedang dipersiapkan. Sedangkan untuk peneliti di bidang pemasaran ingin tahu apa yang akan dibeli pengguna, termasuk mempelajari bagaimana pengguna membuat keputusan pembelian. Oleh sebab itu, dengan tujuan yang berbeda ini akan mengarahkan kedua kelompok tersebut untuk mengembangkan metode penyelidikan yang berbeda pula. Desainer cenderung menggunakan metode observasi kualitatif yang dengannya mereka dapat mempelajari orang secara mendalam, memahami bagaimana mereka melakukan kegiatan mereka dan faktor lingkungan yang ikut berperan [9]. Metode ini sangat memakan waktu, sehingga didalam penelitian ini hanya memeriksa sejumlah kecil orang.. Adapun metode observasi yang dipergunakan adalah metode observasi peneliti sebagai peserta (observer as participant), yaitu kelompok yang sedang diteliti mengetahui tentang keberadaan peneliti, namun peneliti tidak ikut serta melakukan kegiatan dan aktifitas di dalam kelompok yang sedang diteliti.

Lokasi penelitian dilakukan di Masyarakat di Tanjung Siambang Pulau Dompak, Kota Tanjung pinang, Kepulauan Riau, lihat Gambar 2. 


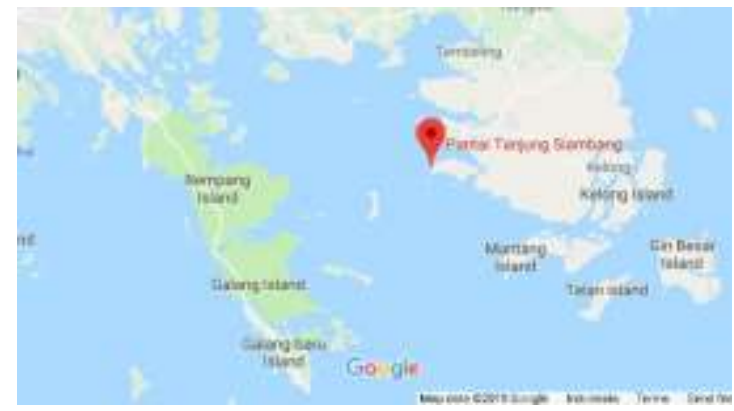

Gambar 2. Lokasi Tanjung Siambang [10]

Metode etnografi yang diterapkan pada penelitian ini adalah peneliti sebagai peserta, dimana kelompok yang sedang diteliti mengetahui tentang keberadaan peneliti, namun peneliti tidak ikut serta melakukan kegiatan dan aktifitas didalam kelompok yang sedang diteliti [11]. Pada Gambar 3 memperlihatkan peneliti melakukan proses pengumpulan informasi terhadap permasalah yang ada di masyarakat.

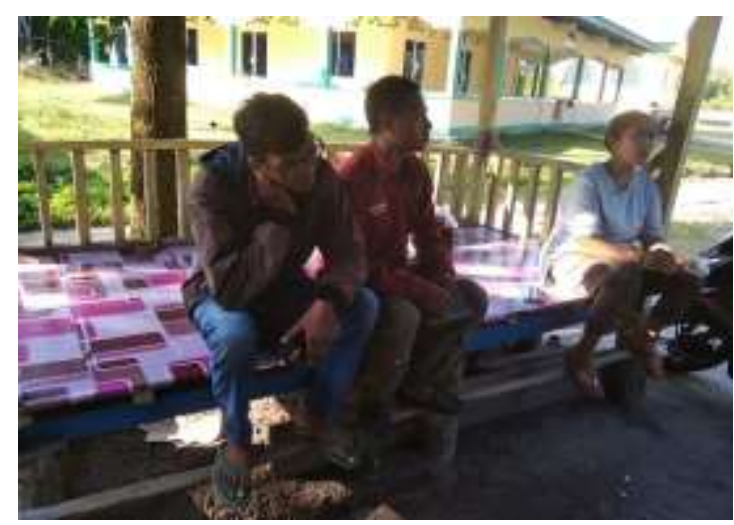

Gambar 3. Mengumpulkan informasi mengenai permasalahan yang terdapat di masyarakat

\section{KARYA UTAMA}

Sistem kerja dari Penetas telur otomatis menggunakan Arduino Uno, Sensor suhu IC LM35, relay AC yang akan mengatur kerja dari lampu pijar dan kipas angin serta penyedia daya mandiri untuk Arduino berupa baterai. Sila lihat

\section{Gambar 4.}

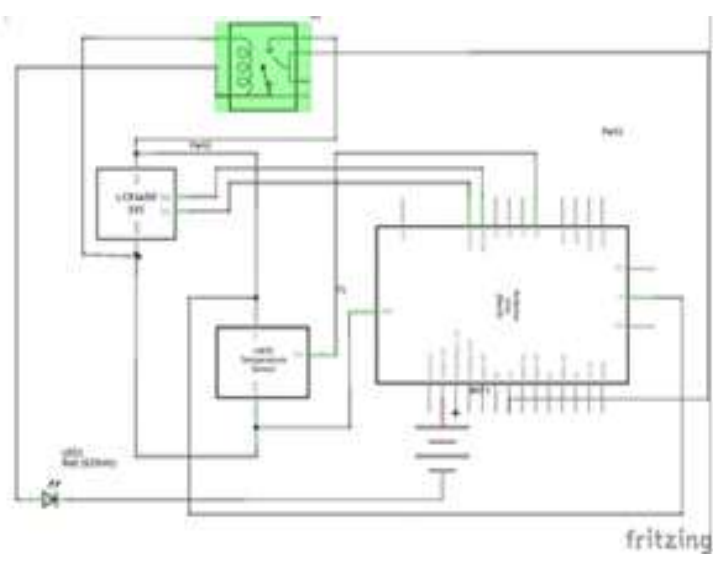

Gambar 4. Rangkaian elektronika sistem penetas telur otomatis menggunakan Arduino Uno dan Sensor suhu IC LM35

\section{Komponen purwarupa}

Adapun komponen yang diperlukan untuk pembuatan purwarupa adalah sebagai berikut :

\subsection{Arduino UNO R3}

Arduino Uno R3 adalah merupakan sebuah mikrokontroller, dimana ikrokontroler tersebut akan memproses input yang diberikan melalui bahasa pemograman open source sehingga akan menghasilkan output. Cukup hubungkan Arduino dengan kabel USB ke PC atau Mac/Linux anda, jalankan software Arduino sudah bisa untuk memprogram chip ATmega328. Sila lihat Gambar 5.

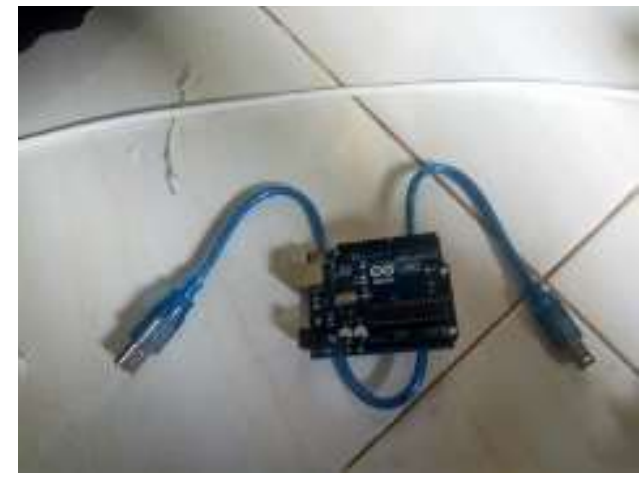

Gambar 5. Arduino Uno 


\subsection{Breadboard}

Breadboard adalah dasar konstruksi sebuah sirkuit elektronik dan merupakan purwarupa dari suatu rangkaian elektronik. Breadboard banyak digunakan untuk merangkai komponen, karena dengan menggunakan breadboard, pembuatan purwarupa tidak memerlukan proses menyolder (langsung tancap). Karena sifatnya yang solderless alias tidak memerlukan solder sehingga dapat digunakan kembali dan dengan demikian sangat cocok digunakan pada tahapan proses pembuatan purwarupa serta membantu dalam berkreasi dalam desain

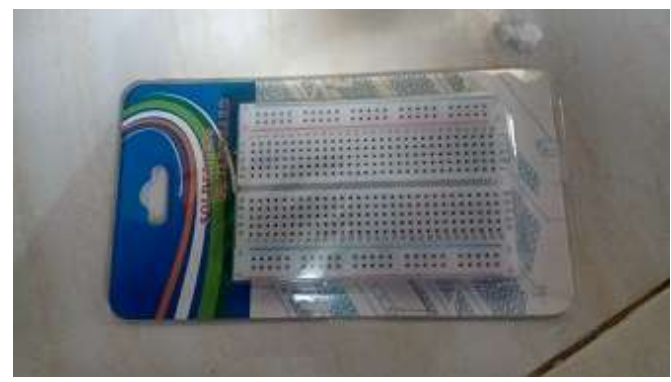

sirkuit elektronika, sila lihat Gambar 6.

Gambar 6. BreadBoard

\subsection{Kabel jumper}

Kabel jumper adalah kabel yang di pergunakan untuk menghubungkan satu komponen dengan komponen lain ataupun menghubungkan jalur rangkaian yang terputus pada breadboard, sila lihat Gambar 7.

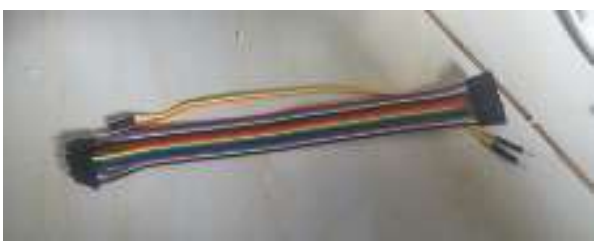

Gambar 7. Kabel Jumper

\subsection{Bank daya}

Bank daya adalah sebuah perangkat yang dipergunakan untuk menyimpan energi listrik ke dalam baterai yang dapat diisi ulang. Adapun cara menggunakan bank daya adalah dengan menghubungkan kabel penghubung perangkat dengan bank daya. Bank daya dapat di isi ulang dengan menghubungkan ke outlet listrik. Sila lihat Gambar 8.

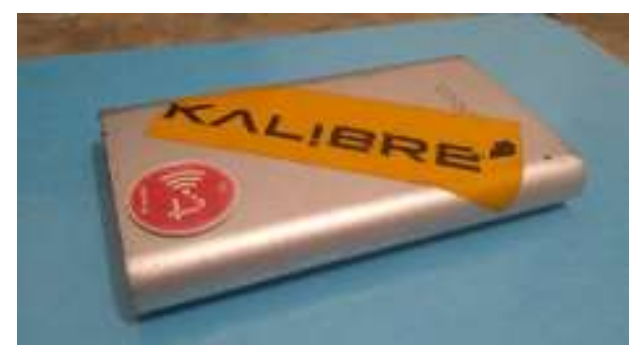

Gambar 8. Bank daya

\subsection{Light Emitting Diode (LED)}

LED adalah sebuah komponen elektronika yang akan menampilkan cahaya apabila diberikan tegangan. Adapun bentuk LED mirip dengan sebuah bohlam (bola lampu) yang kecil dan dapat dipasangkan dengan mudah ke dalam berbagai perangkat elektronika. Berbeda dengan Lampu Pijar, LED tidak memerlukan pembakaran filamen sehingga tidak menimbulkan panas dalam menghasilkan cahaya. Oleh karena itu, LED dengan bentuk yang kecil telah banyak dipergunakan sebagai lampu penerang untuk mengganti lampu tabung. Sila lihat Gambar 9.

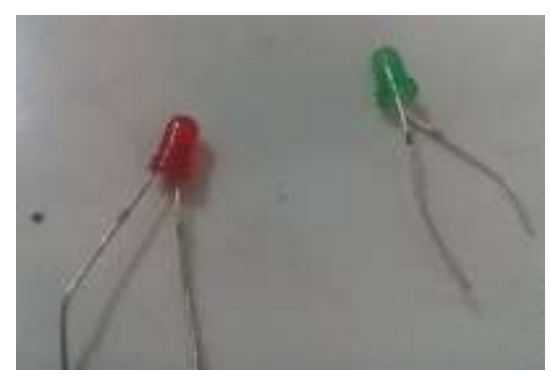

Gambar 9. LED 


\subsection{Relay AC}

Relay adalah sebuah peralatan elektronika yang mengatur hidup dan mati dengan menggunakan elektromagrnetik. Prinsip kerjanya sama dengan sakkar manual yang akan menghubungkan dan memutuskan aliran listrik. Sila lihat

Gambar 10.

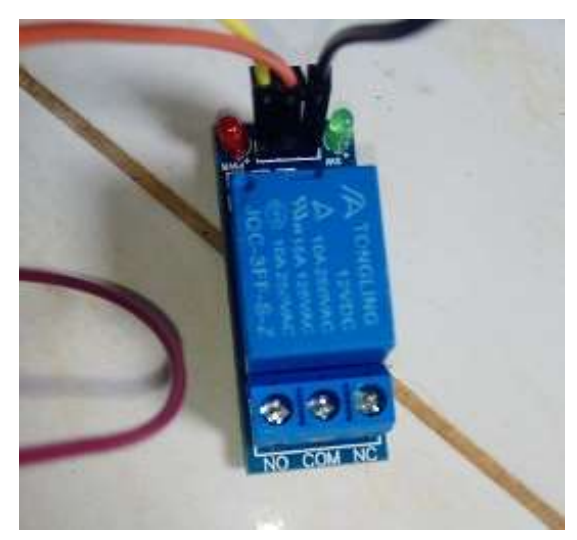

Gambar 10. Relay AC

\subsection{Sensor suhu LM35}

Sensor suhu LM35 adalah komponen elektronika yang memiliki fungsi untuk mengubah besaran suhu menjadi besaran listrik dalam bentuk tegangan. Sila lihat

\section{Gambar 11.}

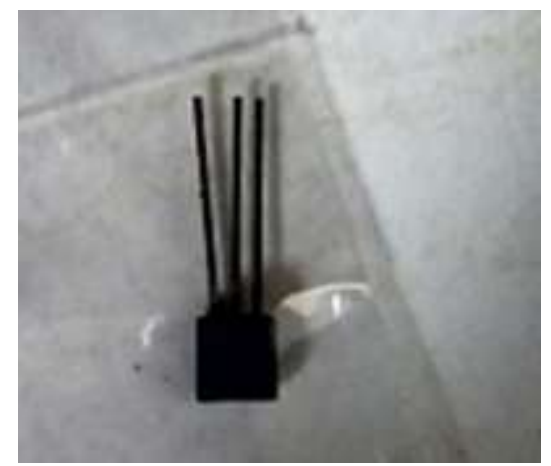

Gambar 11. Sensor suhu LM35

\subsection{Resistor}

Resistor adalah komponen Elektronika Pasif yang memiliki nilai resistansi atau hambatan tertentu yang berfungsi untuk membatasi dan mengatur arus listrik dalam suatu rangkaian Elektronika. Fungsi Resistor di dalam rangkaian elektronika memiliki fungsi pembatas dan pengatur arus listrik, serta pembagi dan penurun tegangan listrik. Sila lihat Gambar 12.

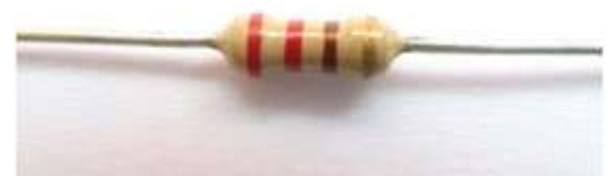

Gambar 12. Resistor

\section{ULASAN KARYA}

Tahapan selanjutnya adalah curahan gagasan permasalahan yang ditemukan di sekolah dari hasil observasi, dimana semua permasalahan yang ditemukan akan di dokumentasikan. Proses ini adalah merupakan tahapan yang penting, karena sangat diharapkan bahwa solusi yang akan dihasilkan adalah merupakan solusi yang dibutuhkan, bukan solusi yang diminta oleh calon pengguna. Pola penyampaian gagasan secara bebas akan sangat diperlukan untuk memotivasi peneliti untuk mampu berpikir inovatif dan kreatif.

Curahan gagasan yang bersifat luas adalah merupakan pondasi bagi rekayasawan untuk mampu menghasilkan sebuah inovasi yang berbasiskan teknologi. Hal ini sering dipahami dengan $\mathrm{T}$ concept, dimaksudkan bahwa inovasi yang dihasilkan memiliki pengaruh yang luas dan mendalam. Pada Gambar 13 dapat dilihat proses pengumpulan masalah-masalah yang sangat berkaitan dengan kejadian di tanjung siambang selama melakukan observasi dan wawancara. 


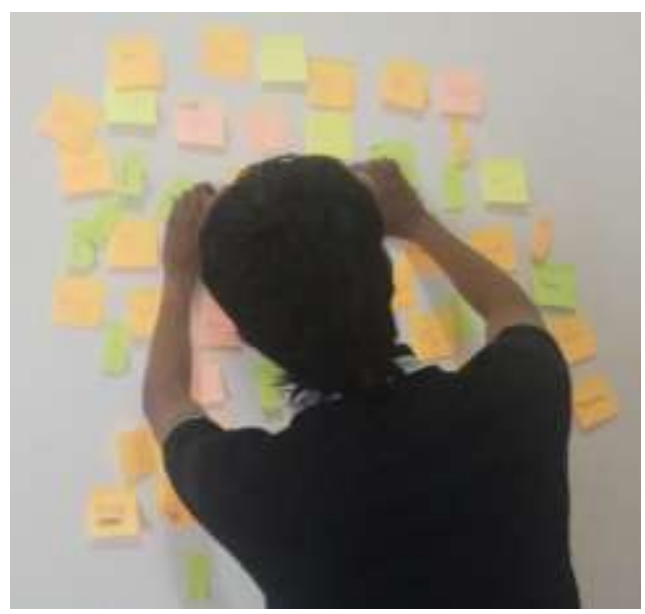

Gambar 13. Proses pengumpulan masalah

Permasalahan utama adalah satu permasalahan yang akan dijadikan landasan untuk langkah penentuan solusi, dalam tahapan ini akan dilakukan proses pengerucutan masalah, dimulai dengan pengelompokan masalah dan selanjutnya di pilih satu masalah saja, lihat Gambar 14. Proses diskusi bersama sesama anggota kelompok dengan saling memberikan penjelasan terhadap masalah yang akan dijadikan masalah utama diperlukan untuk mendapatkan informasiinformasi yang belum dapat disampaikan pada tahapan sebelumnya. Adapun permasalahan utama dari penelitian ini adalah kesulitan peternak ayam untuk menetaskan telor di incubator.

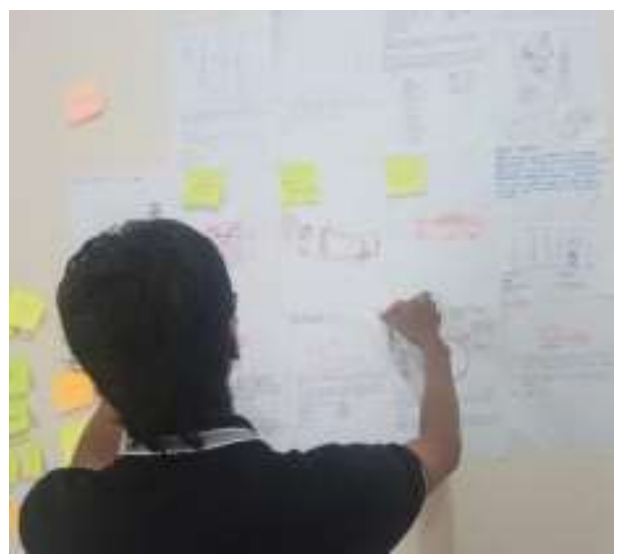

Gambar 14. Proses pengerucutan masalah untuk mendapatkan masalah utama
Tahapan curahan gagasan solusi dari masalah utama dilakukan setelah mendapatkan permasalahan utama. Dalam tahapan ini akan disampaikan beberapa konsep solusi bersama anggota peneliti lainnya. Dengan mempergunakan alat tulis yang dituangkan kedalam sketsa.Pada Gambar 15 menampilkan konsep solusi utama.

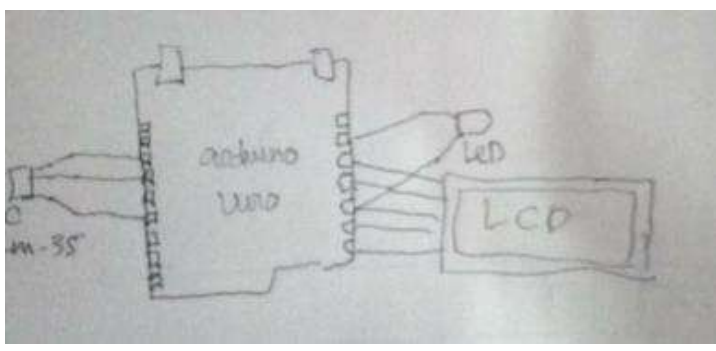

Gambar 15. Konsep solusi utama

\subsection{Purwarupa}

Desainer menggunakan model virtual untuk menggantikan purwarupa nyata dan menganalisisnya menggunakan berbagai jenis simulasi yang bertujuan untuk menciptakan kembali kondisi kehidupan nyata di mana produk perlu beroperasi. Proses ini dibantu oleh program komputer modern, yang dibuat untuk membantu para rekayasawan modern dalam pekerjaan mereka. Model virtual dibuat akan mencerminkan gambar nyata, atau sedekat mungkin dengan nyata [12].

Keuntungan utama dari purwarupa virtual adalah pembuatan purwarupa dari konsep inovasi untuk pengujian awal tidak diperlukan karena setiap penyesuaian akan dilakukan secara langsung dalam realitas virtual dengan mempergunakan simulasi. Purwarupa dapat di explorasi secara virtual dan interaktif, selanjutnya dapat dipelajari dan disimulasikan sebelum implementasi di dunia nyata [13]. 


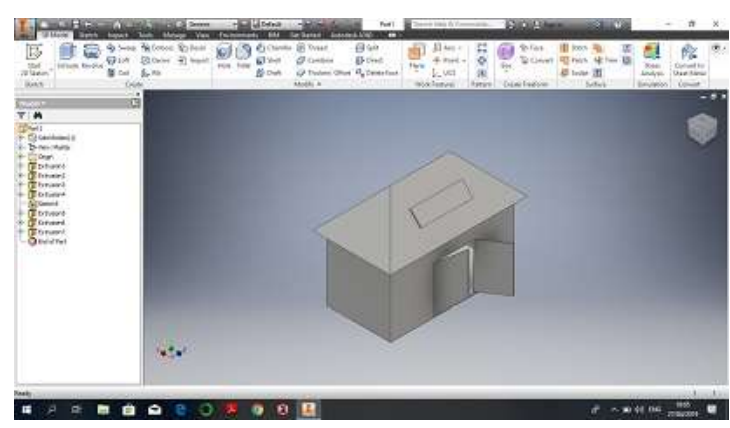

Gambar 16. Purwarupa Penetas telor otomatis

Dalam tahapan ini, telah dimulai menggambar menggunakan komputer untuk mendapatkan tampilan detil awal secara virtual 3 dimensi. Beberapa perubahan dapat dikerjakan secara langsung. Pada Gambar 16 menunjukkan proses transformasi dari sketsa yang digambar di atas kertas ke komputer.

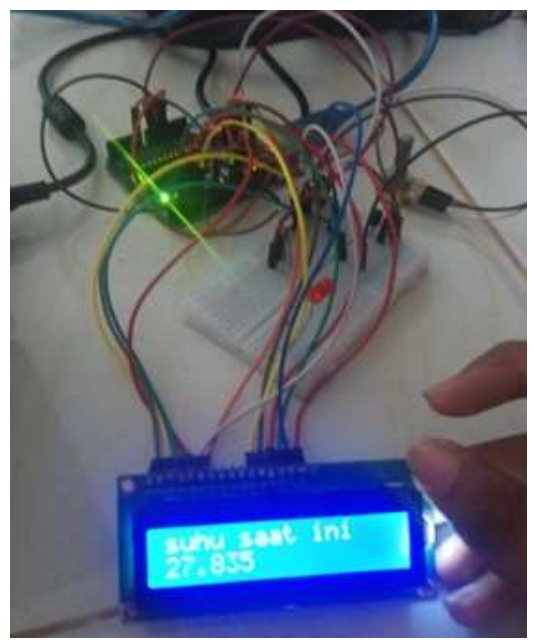

Gambar 17. Purwarupa Sederhana

Tahapan yang sudah mulai memerlukan pembiayaan adalah tahapan pembuatan purwarupa. Oleh sebab itu pada Proses Desain Rekayasa ini, menekankan untuk mampu menghasilkan purwarupa sederhana yang ekonomis dan fleksible, dengan maksud bahwa perubahan rancangan dapat dilakukan dengan mudah dan tidak akan memerlukan pembiayaan yang besar.
Purwarupa dalam tahapan ini lebih dikenal dengan istilah low resolution prototype [14]. Dapat dilihat pada Gambar 17 adalah sebuah purwarupa sederhana dari penetas telor otomatis.

\subsection{Program pada Arduino}

Di bawah ini adalah program yang ditulis pada Arduino untuk dapat menghasilkan luaran sesuai yang di inginkan pada penetas telor otomatis.

Penjelasan tentang program :

Pada Gambar 18 menampilkan tahapan awal didalam pemograman, dengan melakukan inisialisasi program dan memasukkan library yang dibutuhkan.

Include liquidcrystal_I2C adalah library yang kita gunakan dan komponen yang digunakan LCD I2C, sensor LM35, relay chanel. Di dalam program ini sensor LM35 di letakan di pin A0, relay di pin 7.

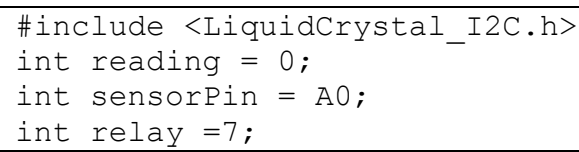

Gambar 18. Inisialisasi program dan memasukkan library yang dibutuhkan

Jika kita menggunakan LCD dengan I2C sebagai serial interface nya maka kita harus mencantumkan alamat dari $\mathrm{I} 2 \mathrm{C}$ nya agar dapat menampilkan text monitor. Sila lihat Gambar 19.

LiquidCrystal I2C $\operatorname{lcd}(0 \times 27,16,2)$;

Gambar 19. Inisialisasi program apabila menggunakan LCDI2C

Sedangkan pada Gambar 20 menampilkan program yang akan dijalankan sekali ketika program penetas otomatis dimulai. 
Void setup kita setting untuk LCD nya yaitu LCD begin dan pada pinmode nya relay sebagai output

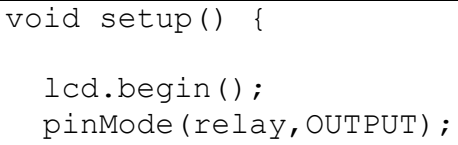

Gambar 20. Program yang dijalankan sekali ketika program penetas telor.

Selanjutnya pada Gambar 21 menampilkan program yang akan dijalankan berulang, dimulai dengan perintah loop.

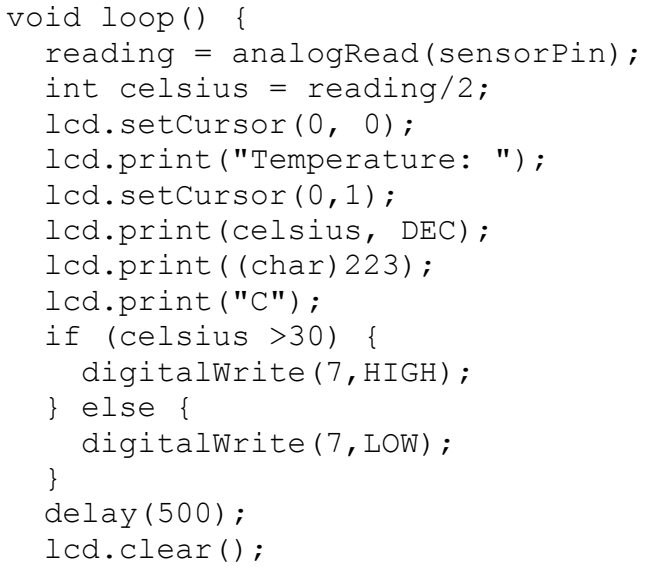

Gambar 21. Program yang akan mengalami pengulangan

Pada void loop kita atur fungsi perulangan dan disini semuanya dibaca berulang kali terus-menerus, disini juga kita tampilkan text monitornya pada set cursor bagian atas yaitu "temperature" dan bagian bawahnya "celcius" . dalam void loop juga menggunakan permisalan IF/ELSE. IF(jika suhu lebih dari 30derajat celcius maka relay akan HIGH dan menghidupkan lampu, karna beban pada relay ini adalah lampu. ELSE (maka jika suhu tidak lebih dari 30 derajat celcius maka relay tidak akan HIGH dan beban lampu tidak akan menyala. Begitulah cara kerja dari program ini.

\section{DAMPAK DAN MANFAAT KEGIATAN}

Pengujian kegunaan adalah proses evaluasi terhadap inovasi yang dirancang dengan berbasis pengguna. Pada tahapan ini pengguna akan berpartisipasi dan berinteraksi secara langsung dengan purwarupa sederhana yang dihasilkan dari proses sebelumnya. Pengguna akan diminta untuk melakukan tugas tertentu atau hanya menjelajahinya secara bebas, sementara perilaku pengguna diamati dan dicatat untuk mengidentifikasi kelemahan desain yang menyebabkan kesalahan atau kesulitan pengguna. Selama pengamatan ini, Setelah kelemahan desain telah diidentifikasi, rekomendasi desain diusulkan untuk meningkatkan kualitas ergonomis produk [15].

Pengalaman pengguna akan memperluas pandangan tentang interaksi produk dengan pengguna dari aspek emosional. Adapun motivasi dari proses pengalaman pengguna adalah untuk mengembangkan pengalaman dan emosi positif. Oleh karena itu, produk harus memenuhi kebutuhan psikologis dan motif pelanggan [16].

Kesuksesan hasil inovasi tidak hanya dilihat dari manfaat dari produk yang akan dihasilkan namun juga perlu memperhatikan faktor pengalaman pengguna, sehingga pengembangan inovasi teknologi tidak lagi hanya tentang mengimplementasikan fitur dan menguji kegunaannya, tetapi juga tentang mendesain produk yang menyenangkan dan mendukung kebutuhan dan nilai-nilai 
dasar manusia. Dengan demikian, pengalaman pengguna dalam tahapan Proses Desain Rekayasa harus menjadi perhatian utama pengembangan produk [17].

Pada Gambar 22 menampilkan pengujian kegunaan purwarupa bersama masyarakat calon pengguna.

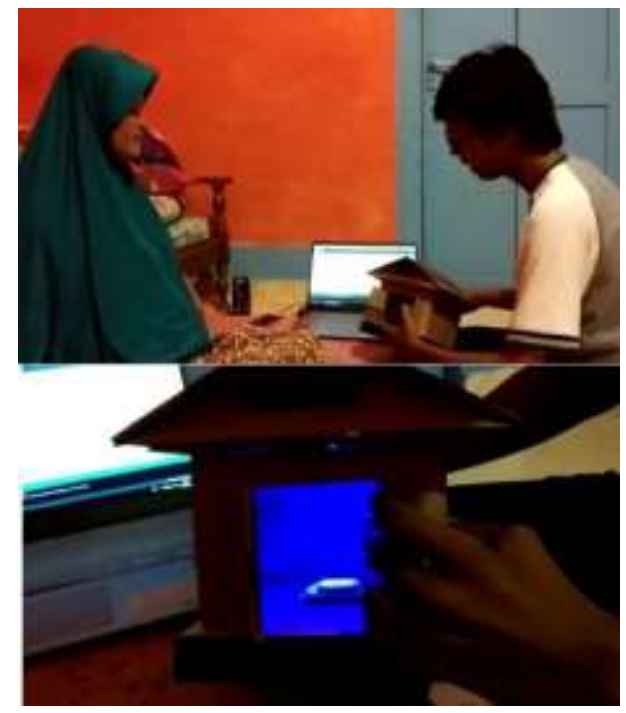

Gambar 22. Pengujian kepada calon pengguna

Pada Tabel 1 menunjukkan hasil pengujian kegunaan bersama seoarang calon pengguna.

Tabel 1. Hasil pengujian kegunaan

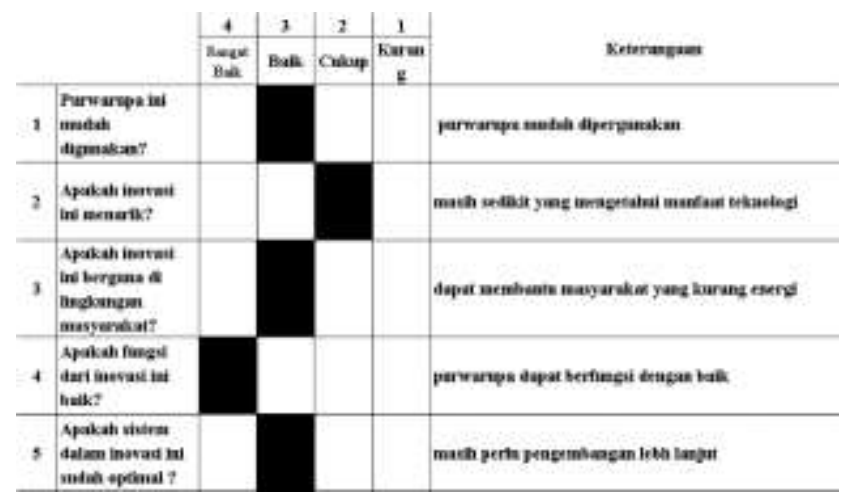

Sedangkan pada Tabel 2 menampilkan biaya yang diperlukan untuk pembuatan purwarupa.
Tabel 2. Estimasi anggaran (RAFTECH Bandung/ Bukalapak, diakses 31 Mei 2019)

\begin{tabular}{|c|c|c|c|}
\hline No. & NAMA EOMPONEN & ЛतLAH(Pes) & HARGA $\left(\mathbb{B}_{2}\right)$ \\
\hline 1 & ARDCLNO CRO & 1 & 53000 \\
\hline 2 & SENSOR SLHULMES & 1 & 10000 \\
\hline 3 & REI AT AC & 1 & 20000 \\
\hline 4 & LED & 1 & 5000 \\
\hline 5 & RESISTOR 250 ahn & 1 & 5000 \\
\hline 7 & KABEL JIMPER MALE-MALE & 1 & 15000 \\
\hline 8 & KABE. JTMPER MALEMALE & 1 & 15000 \\
\hline 11 & PRONECT BOARD & 1 & 14000 \\
\hline & TOTAL & & 137000 \\
\hline
\end{tabular}

Teknologi pemantauan suhu inkubator secara otomatis mempergunakan mikrokontroler yang dapat diterapkan kepada peternak ayam, diharapkan akan dapat membantu peternak untuk meningkatkan jumlah produksi anak ayam dengan meningkatkan jumlah telor yang menetas. Sedangkan teknologi berbasiskan Arduino Uno yang masih tergolong murah dan komponen elektronika yang mudah didapat, tidak memerlukan perlakuan secara khusus sehingga telah dapat menarik minat peternak untuk mendorong sosialisasi terkait pemanfaatan teknologi kepada peternak. Selain itu, kedepannya diharapkan diperlukannya teknologi nirkabel pemantau suhu di inkubator untuk dapat lebih meningkatkan efektifitas peternak dibandingkan dengan pemantauan secara manual, dimana pada saat ini peternak mengunjungi inkubator satu per satu.

\section{KESIMPULAN}

Inovasi berbasis teknologi ini adalah merupakan solusi untuk meningkatkan efektifitas dan produktifitas peternak ayam. Berdasarkan hasil pengujian maka dapat diambil beberapa kesimpulan, yaitu:

- Perancangan inkubator ini telah dapat memudahkan peternak dalam mengelola 
peternakan penetasan telur ayam dengan melakukan pengontrolan suhu secara otomatis

- Perancangan inkubator telah mempergunakan teknologi yang relative murah dan sederhana.

- Peternak dapat melakukan pengontrolan secara visual dengan memperhatikan LCD yang disediakan untuk dapat lebih memastikan bahwa suhu telah bekerja sesuai ketentuan.

Adapun untuk kedepannya dapat disarankan untuk lebih dilakukan pengembagan dari segi fungsi dengan memanfaatkan teknologi nirkabel untuk pemantauan suhu di inkubator. Sedangkan secara umum, masih diperlukan sosialisasi pemanfaatan teknologi kepada para peternak ayam.

\section{DAFTAR PUSTAKA}

[1] Ratag, C.C., (2013), Simulasi sistem pengontrol suhu pada mesin pentas telur berbasis mikrokontroller AT59C52, Jurnal Teknologi Informasi, Vol. 19, No.2, p.148-158

[2] Laksono, A. B., Bachri, A., and Sukin, (2016) Rancang bangun otomatisasi mesin penetas telur sistem turning berbasis mikrokontroler ATMEGA 328, Jurnal Program Studi Teknik Elektro JE-Unisla, Vol 1, No 2.

[3] Karsid, Ramadhan, W. W., and Aziz, R., (2018), Perbandingan kinerja mesin penetas telur otomatis dengan menggunakan kontrol OnOff dan kontrol PWM, Jurnal Matrix, Vol. 8, No. 1, page 1-5
[4] Zulkarnain, (2013), Aplikasi sistem kendali temperatur otomatis pada mesin penetas telus ayam menggunakan sistem fuzzy logic, Skripsi, Universitas Islam Negeri Maulana Malik Ibrahim Malang.

[5] Mido, A. R., (2018), Perancangan mesin otomatis penetas telur berbasis Node MCU dan android, Skripsi, Universitas Teknologi Yogyakarta

[6] Kastner, S and Knight, R. T, (2017), Bringing Kids into the Scientific Review Process. Neuron, Vol. 93, Edisi 1, page 12-14, Elsevier Inc

[7] Irbīte, A., and Strode, A.,(2016), Design thinking models in design research and education, Proceedings of the International Scientific Conference. Vol. IV, page 488-500

[8] The Double Diamond Model of Product Definition and Design [Daring], Tersedia pada https://www.peterme.com/2013/09/2 6/the-double-diamond-model-ofproduct-definition-and-design/ [Diakses : 31 Mei 2019].

[9] Stanford University [Daring], Tersedia pada : Error! Hyperlink reference not valid., [Diakses : $31 \mathrm{Mei}$ 2019]

[10] Google Map [Daring], Tersedia pada :https://www.google.com/maps /place/J1.+Tj.+Siambang/@0.87153 [ Diakses : 31 Mei 2019 ].

[11] Wagner, C., Kawulich, B., and Garner, M., (2012), Collecting Data Through Observation, Doing Social 
Research: A global context, McGraw Hill

[12] Łukaszewicz, K., (2017), Use of CAD Software in the Process of Virtual Prototyping of Machinery, 7th International Conference on Engineering, Project, and Production Management, Procedia Engineering 182, page 425 - 433, Elsevier Ltd

[13] Wang, Z., (2011), Interactive virtual prototyping of a mechanical system considering the environment effect. Part 2: Simulation quality, Comptes Rendus Mécanique, Vol. 339, Edisi 9, p. 605-615, Elsevier Masson SAS

[14] Nusyirwan, D., (2017) Engineering Design Process Engineering Student Centered Experience Learning (ESCEL) di Jurusan Teknik Elektro Universitas Maritim Raja Ali Haji (UMRAH). Jurnal Sustainable Vol. 06, No. 01, page. 24-35

[15] Bastien, J.M. C., (2010) Usability testing: a review of some methodological and technical aspects of the method", International Journal of Medical Informatics, Vol. 79, Edisi 4, page e18-e23, Elsevier Ireland Ltd

[16] von Saucken, C., Lachner, F., and Lindemann, U., (2014), Principles for User Experience What We Can Learn from Bad Examples, International Conference on Kansei Engineering \& Emotion Research

[17] Johnson, G. I., Clegg, C. W., and Ravden, S. J (1989), Towards Practical User Experience Evaluation Methods, Applied
Ergonomics, Volume 20, Edisi 4, p. 255-260, Elsevier Ltd 